\title{
PENGARUH SUDUT SERANG AEROFOIL TERHADAP DISTRIBUSI TEKANAN DAN GAYA ANGKAT
}

\author{
Heri Wibowo \\ Jurusan Pendidikan Teknik Mesin, Fakultas Teknik, Universitas Negeri Yogyakarta \\ heriwbuny@yahoo.com
}

\begin{abstract}
The aerofoils are used to get the lifting force on the design of plane's wings. The lifting force is caused by difference air velocity on upper and lower aerofoil which the magnitude depend on attack angle of aerofoil and air velocity exist surrounding. This experiment aims to show the force vector (pressure distribute) on the aerofoil. The aerofoil is attached by air with konstant velocity. The research procedure is done by change the attack angle of aerofoil on five formation. The surface of aerofoil is connected with pressure gage which is dispersed at 11 point of measurement. The result shows that magnitude of force vector is depended on attack angle of aerofoil. Increasing angle of aerofoil until boundary angle will be followed by increasing air velocity on the point of measurement and finally increase force vector. Upper boundary angle will be followed by decreasing air velocity on the point of measurement and finally decrease force vector.
\end{abstract}

Keywords: Aerofoil, attack angle, wings, lifting force

\begin{abstract}
ABSTRAK
Aerofoil digunakan untuk mendapatkan gaya angkat pada desain sayap pesawat. Gaya angkat disebabkan oleh perbedaan kecepatan udara pada aerofoil atas dan bawah yang besarnya tergantung pada sudut serang aerofoil dan kecepatan udara yang ada disekitarnya. Eksperimen ini bertujuan untuk menampilkan vektor gaya (distribusi tekanan) pada aerofoil. Aerofoil dilekatkan pada udara dengan kecepatan konstan. Prosedur penelitian dilakukan dengan cara mengubah sudut serang aerofoil pada lima formasi. Permukaan aerofoil dihubungkan dengan alat ukur tekanan yang tersebar pada 11 titik pengukuran. Hasil menunjukkan bahwa besarnya vektor gaya bergantung pada sudut serang aerofoil. Sudut aerofoil yang meningkat hingga sudut batas akan diikuti dengan peningkatan kecepatan udara pada titik pengukuran dan akhirnya meningkatkan vektor gaya. Sudut batas atas akan diikuti oleh penurunan kecepatan udara pada titik pengukuran dan akhirnya menurunkan vektor gaya.
\end{abstract}

Kata kunci: aerofoil, sudut serang, sayap, daya angkat

\section{PENDAHULUAN}

Faktor aerodinamik pada desain suatu kendaraan maupun pesawat terbang, merupakan suatu hal yang selalu mendapat perhatian. Hal ini berkaitan dengan gaya tahanan maupun gaya angkat yang terjadi pada kendaraan yang disebabkan oleh udara yang bergerak di sekeliling kendaraan tersebut. Aliran udara yang terjadi di sekeliling benda memiliki kecepatan dan tekanan tertentu. Selain itu, benda yang berada di dalam aliran udara bergerak juga akan mengalami gaya-gaya udara. Gaya-gaya udara ini dapat dibagi menjadi 2 komponen pokok yaitu: (a) komponen yang tegak lurus terhadap aliran udara disebut gaya angkat (lift) dan (b) komponen yang bekerja sejajar dengan aliran udara disebut dengan gaya tahanan (drag). Gaya drag timbul karena pengaruh gaya antara lain gaya gesek pada permukaan benda dan gaya tahanan tekanan (Szubert et al. 2016). Gaya drag pada artikel ini tidak ditampilkan karena komponen gaya tahanan yaitu gaya gesek tidak dapat diukur pada eksperimen ini. Sistem pada aerofoil akan mengubah insentitas gaya dengan ketidak-seimbangan distribusi tekanan statis pada permukaan dan ketidakseimbangan tegangan geser pada distribusi tekanan tersebut.

Aerofoil merupakan model bentuk melintang dari sayap pesawat yang berfungsi untuk mendapatkan gaya angkat pada pesawat 
yang berjalan pada kecepatan tertentu. Besarnya gaya angkat aerofoil sangat tergantung pada sudut serangnya (Haque et al. 2015). Dengan bertambahnya sudut serang maka akan menambah gaya angkat aerofoil tersebut sampai batas sudut maksimal (Alam et al. 2014).

Kecepatan udara pada aerofoil, antara titik satu dengan titik yang lain besarnya berbeda. Hal ini yang menyebabkan adanya distribusi tekanan yang tidak merata pada aerofoil (Bagade et al. 2014). Persamaan Bernaulli menjelaskan bahwa semakin cepat udara yang bekerja disuatu tempat maka tekanan pada tempat itu akan semakin berkurang (Venkataraman et al. 2014). Perbedaan tekanan pada barometer mengacu pada perbedaan ketinggian pada pembacaan manometer. Semakin tinggi perbedaan ketinggian yang terbaca, maka semakin tinggi pula tekanan terukur terhadap tekanan udara bebas.

Dengan menggunakan model aerofoil sebagai prototype dari sayap pesawat diharapkan dapat memberikan data utama untuk analisa pada aeromodelling, sehingga menjadi salah satu referensi dalam mendesain sayap pesawat baik pesawat terbang maupun pesawat aeromodelling.

\section{METODE}

Penelitian dilaksanakan secara eksperimental dengan menggunakan aerofoil yang berada dalam terowongan angin yang panjang, dengan tujuan agar udara yang mengenai aerofoil bersifat laminer. Aerofoil dibuat bentuk simetri dimaksudkan lebih mempermudah dalam menganalisa gaya yang ada pada aerofoil.

Variabel tetap yang ditentukan sebelum pelaksanaan pengujian antara lain: sudut serang $(\alpha)$, kecepatan udara indikator sebelum mengenai aerofoil $(V \infty)$ dan rapat massa $\operatorname{udara}\left(\rho_{u d}\right)$. Sedangkan variabel bebas yang merupakan variabel yang didapatkan setelah pengujian adalah tinggi manometer (h), kecepatan udara lokal $(V)$ dan distribusi tekanan lokal pada titik yang ditinjau $(C p)$.

Untuk menentukan kecepatan udara lokal

(V) pada suatu titik digunakan persamaan (Dwinnell, dkk, 1989):

$V^{2}=\frac{2 \times \Delta p}{\rho_{u d}}=13,41 . \Delta \mathrm{h}$

dimana

$\Delta p=$ perbedaan tekanan pada manometer $\left(\mathrm{N} / \mathrm{m}^{2}\right)$

$\Delta \mathrm{h}=$ perbedaan ketinggian pada pembacaan manometer $(\mathrm{m})$

$\rho_{u d}=$ rapat massa udara $\left(\mathrm{kg} / \mathrm{m}^{3}\right)$

Udara merupakan campuran dari gas-gas dengan uap air. Dengan mengukur besarnya kelembaban udara saat percobaan beserta suhu dan tekanannya, maka rapat massa udara $\left(\rho_{u d}\right)$ dapat ditentukan dengan persamaan (White, $d k k, 1988)$ :

$\rho_{u d}=\frac{P-P v}{g \cdot R_{u d} \cdot T}+\frac{P v}{g \cdot R_{\text {air }} \cdot T} \ldots \ldots \ldots \ldots$

Dimana:

$P=$ tekanan udara rata-rata saat pengukuran $\left(\mathrm{N} / \mathrm{m}^{2}\right)$

$T=$ suhu rata rata saat pengukuran $\left({ }^{0} \mathrm{~K}\right)$

$\mathrm{g}=$ tetapan gravitasi $\left(\mathrm{m} / \mathrm{s}^{2}\right)$

$P v=$ tekanan parsial uap air di udara $\left(\mathrm{N} / \mathrm{m}^{2}\right)$

$R_{u d}$ dan $R_{\text {air }}=$ konstanta gas (udara dan uap air) $\left(\mathrm{J} / \mathrm{kg}\right.$-mole $\left.{ }^{0} \mathrm{~K}\right)$

Untuk memperoleh distribusi tekanan setiap titik di permukaan bagian atas aerofoil, maka harus diketahui kecepatan udara lokal pada titik tersebut dengan persamaan di atas. Distribusi tekanan pada aerofoil dicari dengan persamaan (Dwinnell, dkk, 1989):

$$
C p=1-\left(\frac{V}{V \infty}\right)^{2}
$$

Dimana:

$V=$ kecepatan udara lokal pada tiap titik $(\mathrm{m} / \mathrm{s})$

$V \infty=$ kecepatan udara indikator sebelum mengenai aerofoil $(\mathrm{m} / \mathrm{s})$.

Besarnya koefisien gaya angkat menurut James $H$. Dwinnell dapat ditentukan dari persamaan koefisien gaya angkat $\left(C_{L}\right)$ : 
$C_{L}=a \cdot\left(\alpha-\alpha_{L}\right)$

Dimana:

$\mathrm{a}=$ gradien kemiringan kurva sampai $C_{L}$ maksimum,

$\alpha_{L}=$ sudut serang pada saat $C_{L}$ berharga nol.

Dimensi aerofoil sebagai benda uji mempunyai lebar $106 \mathrm{~mm}$ dan terdapat 11 lobang pada salah satu sisi yaitu sisi atas aerofoil yang dihubungkan ke alat pengukur tekanan (manometer). Manometer yang digunakan berbentuk $U$ yang berisi air. Perbedaan ketinggian yang diukur pada manometer merupakan ketinggian pengukuran saat penelitian dikurangi ketinggian awal. Aerofoil dapat diputar menurut sumbunya yang diistilahkan sebagai sudut serang. Bila aerofoil diputar searah jarum jam, maka sudut serang dianggap positif $(+)$, dan sebaliknya sebagai sudut serang negatif (-).

Waktu tunggu diperlukan pada saat pengambilan data agar aliran udara menjadi steadi (konstan) dan tekanan udara yang mengenai aerofoil juga menjadi steadi yang ditandai kestabilan manometer. Hal ini dimaksudkan agar distribusi tekanan yang dihasilkan dapat terbaca lebih teliti dan akurat.

Udara yang diberikan melalui aerofoil mempunyai kecepatan tertentu yaitu $18 \mathrm{~m} / \mathrm{s}$ sesuai dengan standar mesin uji yang digunakan. Setelah udara melewati aerofoil, maka pada manometer akan menunjukkan perubahan ketinggian dari keadaan awal sebelum diberi aliran udara. Dengan persamaan 1, dapat diukur besarnya kecepatan udara lokal pada titik tersebut dengan perubahan ketinggian manometer. Pengukuran diulangi kembali dengan mengubah sudut serang aerofoil yaitu untuk sudut : $-10^{0},-5^{0}, 0^{0}, 5^{0}, 10^{0}$., sehingga semua titik dengan berbagai sudut serang dapat diperoleh besarnya kecepatan udara lokal.

\section{HASIL DAN PEMBAHASAN}

Dari eksperimen yang dilakukan, diperoleh ketinggian cairan dalam manometer yang berbeda-beda antara satu titik dengan titik yang lain yang terdapat pada permukaan aerofoil. Untuk mendapatkan kecepatan udara lokal $(V)$ pada aerofoil di setiap titik, maka digunakan persamaan (1) diatas. Sedangkan distribusi tekanan pada titik yang ditinjau dengan memasukkan harga $V$ kedalam persamaan (4) diatas.

Sebelum dan sesudah pengujian, telah diambil data-data pokok yang merupakan harga awal perhitungan. Data-data tersebut kemudian diambil rata-rata dari data sebelum dan sesudah perhitungan yaitu : $\mathrm{T}=301,75{ }^{0} \mathrm{~K}, \mathrm{P}_{\text {udara }}=$ $1,025 \times 10^{5} \mathrm{~N} / \mathrm{m}^{2}$, dan kelembaban udara $=$ $77 \%$.

Gambar diagram 1 dan 2 menunjukkan hasil pengujian kecepatan lokal $(V)$ dan distribusi tekanan $(C p)$ dengan pembacaan beda ketinggian cairan pada manometer tiap titik pengukuran yang terdapat pada permukaan aerofoil. Pengukuran dilaksanakan pada sudut serang $-10^{0},-5^{0}, 0^{0}, 5^{0}, 10^{\circ}$.

Dari hasil pengujian aerofoil, kecepatan udara lokal dan distribusi tekanan tiap titik pengukuran berbeda-beda untuk sudut serang yang sama. Harga distribusi tekanan $(C p)$ berharga positif, berarti ada gaya tekan pada titik yang ditinjau. Apabila ditampilkan dengan vektor gaya, didapatkan arah gaya yang kebawah atau gaya yang berlawanan dengan gaya angkat. Sebaliknya bila harga distribusi tekanan $(C p)$ negatif maka gaya tarik pada titik yang ditinjau atau dengan arah vektor berupa gaya angkat.

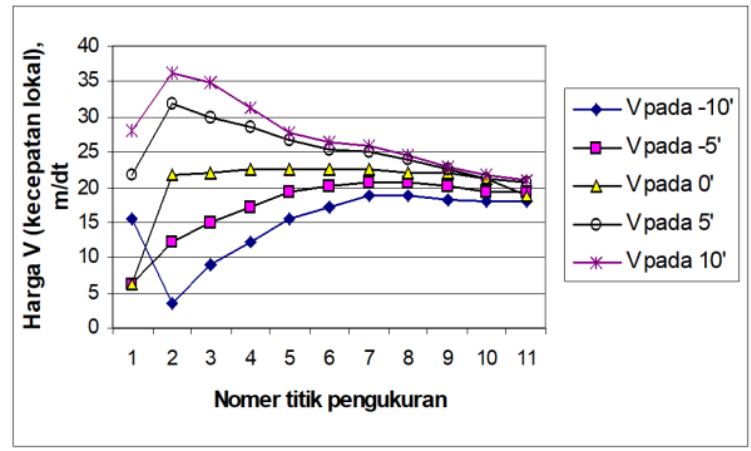

Gambar 1. Harga kecepatan lokal dengan 5 variasi sudut serang 
Apabila dilihat dihasil perhitungan diatas, maka tampak gaya kebawah terbesar berada pada titik 2 dengan sudut aerofoil $-10^{0}$. Sedangkan gaya angkat terbesar berada pada titik 2 dengan sudut kemiringan $10^{\circ}$. Besarnya $C p$ bisa digambarkan pada grafik aerofoil, yang merupakan distribusi tekanan (vektor gaya) tiap titik pada aerofoil dengan sudut serang aerofoil yang bervariasi (Gambar 3 sampai Gambar 7).

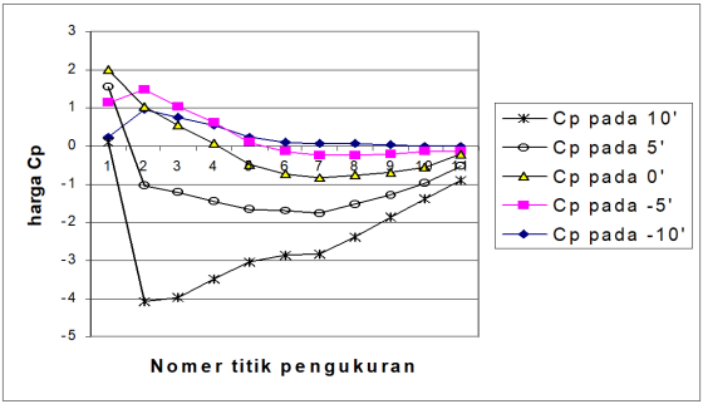

Gambar 2. Harga distribusi tekanan (Cp) dengan 5 variasi sudut serang

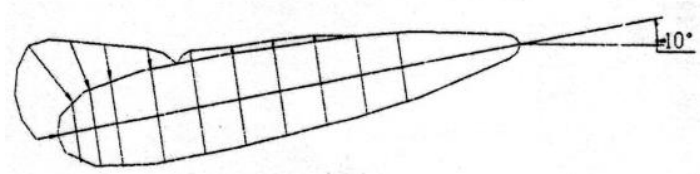

Gambar 3. Distribusi tekanan (vektor gaya) pada sudut serang -100 .

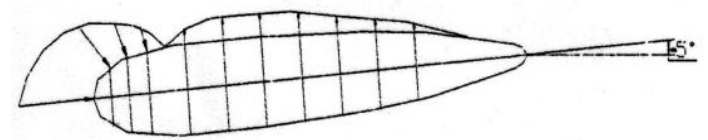

Gambar 4. Distribusi tekanan (vektor gaya) pada sudut serang -50 .

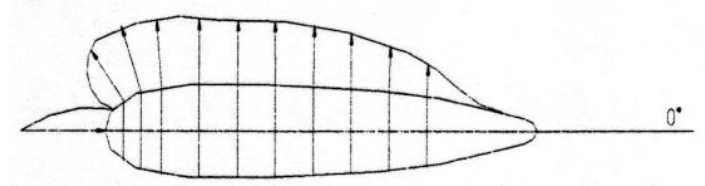

Gambar 5. Distribusi tekanan (vektor gaya) pada sudut serang $0^{0}$.

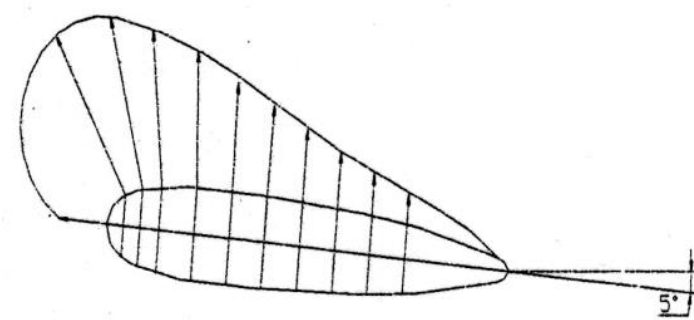

Gambar 6. Distribusi tekanan (vektor gaya) pada sudut serang $5^{0}$.

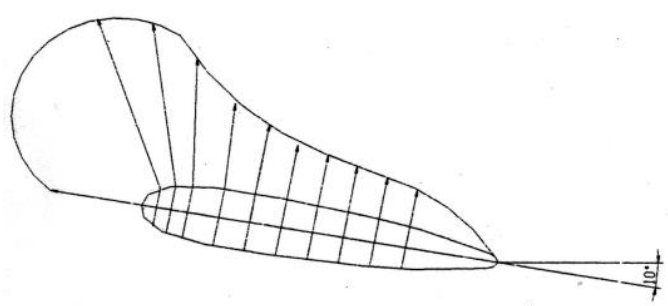

Gambar 7. Distribusi tekanan (vektor gaya) pada sudut serang $10^{\circ}$.

Bila dibandingkan distribusi tekanan pada sudut serang yang berbeda, maka akan terlihat bahwa sudut serang sangat menentukan distribusi tekanan suatu aerofoil (Ismail \& Vijayaraghavan 2015). Apabila sudut serang negatif (-), maka arah gaya tekan lokal akan kebawah, sehingga berlawanan gaya angkat. Namun pada arah sudut serang $0^{0}$ dan positif (+), maka akan terjadi gaya angkat yang keatas. Semakin besar sudut, maka akan semakin besar gaya angkatnya, sampai sudut maksimal.

Hasil distribusi tekanan pada aerofoil dengan beberapa sudut serang senada dengan penelitian Zhou et al. (2017) yang menunjukkan kejutan pada koefisien distribusi tekanan dengan adanya perubahan sudut serang pada aerofoil seperti ditampilkan pada gambar 8 .

Dengan menggunakan $(V \infty)=18 \mathrm{~m} / \mathrm{s}$, sudut $\alpha$ dalam radian dan panjang aerofoil adalah 1 meter, diperoleh harga $C_{L}$ dan $F_{L}$ untuk berbagai sudut serang yang ditampilkan pada tabel 1.

Dari Tabel 1 dapat diketahui gaya angkat total aerofoil, dengan semakin besar sudut serang akan menambah gaya angkat. Namun 
sudut serang aerofoil memiliki nilai maksimum, yang pada penelitian ini tidak bisa diketahui besarnya. Apabila aerofoil bekerja melebihi sudut serang maksimum tersebut, maka aerofoil akan kehilangan gaya angkatnya.

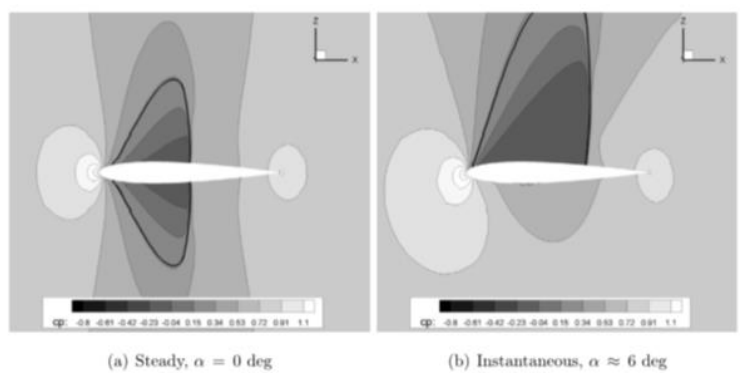

Gambar 8. Perubahan koefisien distribusi tekanan pada aerofoil (Zhou et al. 2017).

Tabel 1. Variasi sudut serang terhadap koefisien gaya angkat dan gaya angkat total pada aerofoil

\begin{tabular}{cccc}
\hline No & $\begin{array}{c}\text { Sudut } \\
\text { serang }\end{array}$ & $\begin{array}{c}\text { Koefisien } \\
\text { gaya angkat }\end{array}$ & $\begin{array}{c}\mathrm{F}_{\mathrm{L}} \text { (gaya } \\
\text { angkat total) }\end{array}$ \\
\hline 1 & $-10^{0}$ & $-0,60$ & $-12,48 \mathrm{~kg}$ \\
2 & $-5^{0}$ & $-0,20$ & $-4,16 \mathrm{~kg}$ \\
3 & $0^{0}$ & 0,20 & $4,16 \mathrm{~kg}$ \\
4 & $5^{0}$ & 0,60 & $12,48 \mathrm{~kg}$ \\
5 & $10^{0}$ & 1,00 & $24,96 \mathrm{~kg}$ \\
\hline
\end{tabular}

\section{SIMPULAN}

Berdasarkan pembahasan tersebut maka dapat diketahui bahwa: (1) semakin besar sudut serang aerofoil, gaya angkat akan semakin besar yang ditunjukkan oleh diagram distribusi tekanan (vektor gaya). Sudut serang ini memiliki harga maksimum, apabila aerofoil bekerja diatas sudut maksimum tersebut maka gaya angkat akan hilang, (2) Jika kecepatan aliran udara lokal $(V)$ lebih besar dari kecepatan aliran udara indikator $(V \infty)$, maka harga distribusi tekanan $(C P)$ akan negatif atau ada gaya tarik pada titik yang ditinjau. Begitu pula sebaliknya, bila $V$ lebih kecil dari $(V \infty)$ maka $C p$ akan positif atau ada gaya tekan pada titik yang ditinjau.

\section{DAFTAR RUJUKAN}

Alam, G.M.J., Taher, A. \& Islam, Q., 2014. Investigation of the aerodynamic characteristics of an aerofoil shaped fuselage UAV model. Procedia Engineering, 90, pp.225-231.

Bagade, P.M., Bhumkar, Y.G. \& Sengupta, T.K., 2014. Computers \& Fluids An improved orthogonal grid generation method for solving flows past highly cambered aerofoils with and without roughness elements. COMPUTERS AND FLUIDS, 103, pp.275-289.

Dwinnell and James H., 1949. Principle of Aerodinamics, First Edition. Mc Graw Hill Book Company: New York

Haque, M.N., Ali, M. \& Ara, I., 2015. Experimental investigation on the performance of NACA 4412 aerofoil with curved leading edge planform. Procedia Engineering, 105(Icte 2014), pp.232-240.

Ismail, F. \& Vijayaraghavan, K., 2015. The effects of aerofoil pro fi le modi fi cation on a vertical axis wind turbine performance., , 80, pp.20-31.

Szubert, D. et al., 2016. European Journal of Mechanics B / Fluids Numerical study of the turbulent transonic interaction and transition location effect involving optimisation around a supercritical aerofoil. European Journal of Mechanics B/Fluids, 55, pp.380-393.

Venkataraman, D., Bottaro, A. \& Govindarajan, R., 2014. A minimal model for flow control on an aerofoil using a poro-elastic coating. Journal of Fluids and Structures, 47, pp.150-164.

White and Frank M., 1988. Mekanika Fluida, Edisi kedua jilid 1. Jakarta: Erlangga

Zhou, Q. et al., 2017. Reduced order unsteady aerodynamic model of a rigid aerofoil in gust encounters. Aerospace Science and Technology, 63, pp.203-213. 